\title{
The Case for Cognitive Neuropsychological Remediation
}

\author{
Marlene Behrmann, MA (Speech Path.) (Witwatersrand) \\ Sharon Herdan, BA (Sp. and H. Therapy) (Witwatersrand) \\ Department of Speech Pathology and Audiology, \\ University of the Witwatersrand, Johannesburg
}

\begin{abstract}
Developments in the field of cognitive neuropsychology have recently begun to have an impact on therapeutic approaches to aphasia. Increasingly, clinicians have started adopting theoretical models of normal cognitive processing for the assessment and rehabilitation of individuals with acquired language deficits. This study describes and evaluates a single case, tested and treated within this framework. The subject, a surface dysgraphic, was assessed in detail pre-therapy and a deficit in lexical processing was diagnosed. Treatment designed to stimulate the lexical route of writing was undertaken and post-therapy evaluation was conducted. The results revealed a significant improvement in the writing of both regular and irregular treated words with generalisation to certain untreated words. Such improvement was shown to be a direct consequence of the intervention procedure. Therapeutic findings strengthen the basis of cognitive processing models which, in turn, provide a streamlined clinical framework for the practitioner.
\end{abstract}

\section{OPSOMMING}

Resente ontwikkeling in die vakgebied van kognitiewe neuropsigologie begin om 'n invloed uit te oefen op terapeutiese benaderings tot afusie. Terapeute begin toenemend om teoretiese modelle van normale kognitiewe prosessering aan te wend vir die evaluering en rehabilitering van individue met verworwe taalafwykings. Hierdie studie besknf en evalueer 'n enkele geval wat binne hierdie raamwerk geëvalueer en behandel is. Voor die aanvang van die behandeling is 'n diepte-evaluasie op 'n pasiënt met oppervlakdisgrafie uitgevoer en 'n afwyking in leksikale prosessering is gediagnoseer. Behandeling gerig op die stimulering van die leksikale roete van skryfvermoëns is uitgevoer en die pasiënt is na afloop van die behandeling geherevalueer. Resultate dui op 'n beduidende verbetering in die skryf van beide reëlmatige en onreëlmatige behandelde woorde met veralgemening na sekere onbehandelde woorde. Hierdie verbetering is bewys om 'n direkte gevolg van die intervensieprosedure te wees. Terapeutiese bevindinge verstrek die basis van kognitiewe prosesseringsmodelle wat op hulle beurt 'n gerasionaliseerde kliniese raamwerk aan die klinikus verskaf.

The last decade has witnessed the rapid expansion of a discipline which has come to be called cognitive neuropsychology. This discipline postulates that an information-processing system, consisting of a number of modular subcomponents, underlies the normal execution of any cognitive activity (Coltheart 1983, 1985). These modular, domain-specific subcomponents function independently and are interconnected by a network of pathways. Whereas all the subsystems function adequately in normals, they are susceptible to discrete disruption following brain damage. Brain damage, thus, leads to observable dissociations between functions. Such dissociations have been studied in detail and have evolved into a detailed description of the various patterns of acquired cognitive deficits (see Coltheart 1980).

The study of brain damaged patients within the cognitive neuropsychological paradigm has been informative on a number of levels. It has confirmed the existence of theoretically postulated dissociations and has lent credibility to the existing theoretical models, especially in the field of acquired dyslexia. A further benefit of such an approach has been in the clinical sphere. Sophisticated diagnostic methods have evolved in order to assess the independent functioning of the modular subcomponents. Additionally, and more recently, remediation programs designed to restore the malfunctioning subsystem, have been described in the literature (Behrmann 1987; Byng and Coltheart 1986 and de Partz 1986). The cognitive neuropsychological approach has facilitated the locating of a specific acquired deficit in precise terms and has then provided guidelines for formulating an individually tailored treatment program. According to Hatfield (1983), this new orientation has made it possible to develop new methods which depend on a wellthought out theory of normal cognitive processing.

A basic concern of the above cited remediation studies is methodological integrity. Treatment studies have always been subject to methodological inadequacies and as such, results have been ambiguous and undefined. In many instances, it has been impossible to determine whether the positive findings were attributable to the treatment itself or to other co-occurring but non-specific causes such as spontaneous recovery or increased motivation (Byng and Coltheart 1986). The cognitive neuropsychological remediation studies, on the other hand, have been designed in such a way that the outcome of therapy may be unequivocally interpreted and as such, satisfy rigorous methodological criteria.

The purpose of this paper is to describe a remediation study based on the cognitive neuropsychological theory of writing. In recent years, models of the normal writing process have become increasingly well developed and detailed investigations of the acquired dysgraphias have been under- 
taken (Margolin 1984; Patterson and Shewell 1987). Despite the fact that such theoretical development has much potential for therapeutic application, there are remarkably few treatment studies in this area. The present study was designed to apply a model of normal writing to the remediation of an acquired agraphia.

As in most current models of the normal writing process, the writing model adopted for this study includes two major routes (see Figure 1). The phonological route involves the segmental translation from phonology to orthography spelling of words directly from the lexicon and are thus forced to rely on the phonological route whereby phonological segments are translated into orthographic representations (Ellis 1984; Hatfield and Patterson 1983). The outcome of this is that irregular and homophonic spelling is adversely affected and since phoneme-grapheme conversion is used, resulting spelling errors are phonologically plausible for example, 'yacht' may be written 'yot'.

Previous studies (Beauvois and Derouésné 1981; Hatfield

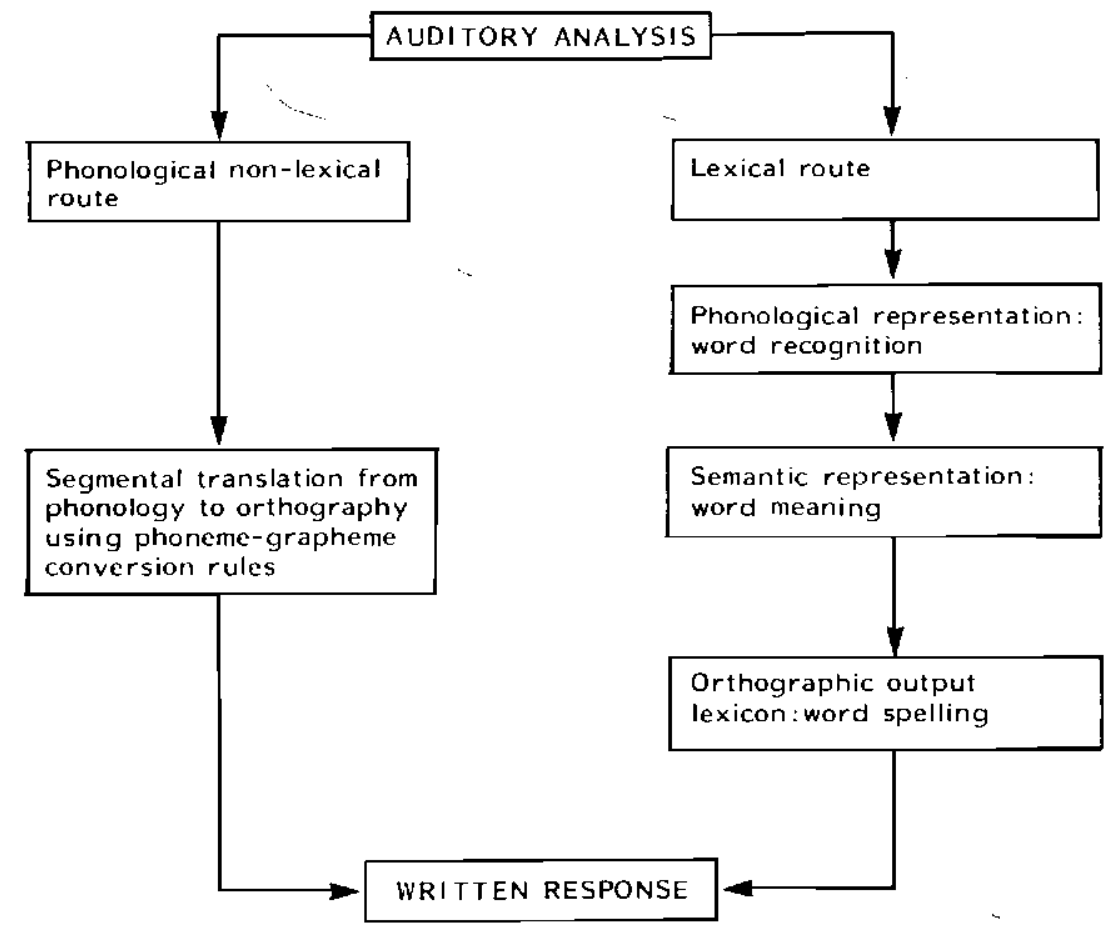

Figure 1: Simplified information processing model of two major routes for single word writing to dictation (after Ellis 1984: Patterson 1980.)

through the application of rules of phoneme-to-graphemeconversion. This route may only be utilised to write regular words whose spelling conforms to the spelling conventions of the language. In addition, one may use this route for assembling the spelling of unfamiliar words or non-words which do not have prior entries in the lexicon. The second major route, the lexical route, involves an association between word spelling and its meaning. Thus, the writer must recognise the phonological input of the dictated word and must access its semantic representation and orthographic form. This may only be achieved with words which have prior entries in the lexicon, i.e., are real words which have been encountered previously. The use of the lexical procedure is critical for spelling irregular words (which cannot be assembled through phoneme-grapheme conversion) and homophonic words (which are phonologically identical but differ in orthographic representation and semantics) (Hatfield and Patterson 1983; Margolin 1984).

Surface dysgraphia is one of the patterns of deficit identified on the basis of models such as the one above. This problem, alternatively termed lexical or orthographic dysgraphia, arises from the defective functioning of the lexical route. Patients with this disorder have lost the ability to access the and Patterson 1983) have focussed on the assessment and classification of acquired surface dysgraphia. Beauvois and Derouésné (1981), for example, reported that their subject, R.G. wrote almost all non-words correctly but that his real word spelling depended on the degree of orthographic ambiguity between sound and print. As words became less regular in their spelling pattern, so his performance deteriorated. Hatfield and Patterson's (1983) subject, T.P. also spelled via the non-lexical routine. He too showed superior performance on regular compared with irregular words and many of his errors were phonologically plausible (e.g., laugh - laf). Treatment of this disorder was undertaken by Hatfield (1983) who described a positive therapy outcome for her surface dysgraphic subject. Another study of surface dysgraphia treatment, undertaken by Behrmann \{1987\}, was devoted to the retraining of the subject's lexical route through the use of homophonic rather than irregular words. The subject benefitted from this intervention; showing marked improvement on treated homophones (from $49 \%$ to $67 \%$ ). In addition, the subject improved on writing untreated irregular words $\{32 \%$ to $67 \%$ across two lists $\}$, implying that a broad, rather than a specific, change within lexical processing had been implemented. Minimal improvement on untreated homophones was noted, suggesting that the 
lexical route was not entirely restored or alternatively, word-specific learning is necessary for homophones.

The subject of the present study, CCM, participated in the Behrmann (1987) study and as is evident, did not achieve perfect scores on irregular word writing. She has subsequently participated in a second phase of the treatment program and the results of this phase are reported here.

\section{AIMS}

The aim of the present study was to investigate the efficacy of a treatment program conducted within a cognitive neuropsychological framework, on a subject with acquired dysgraphia. More specifically, this study was designed to investigate the subject's present use of the lexical procedure in writing to dictation, and to implement a therapy procedure to further enhance the use of the lexical route in writing.

\section{SUBJECT DESCRIPTION}

\section{a. Case history}

CCM suffered a cerebro-vascular accident (CVA) in June 1984, at the age of 53 years. A CT scan suggested that the CVA involved the middle cerebral artery in the left temporoparietal region. Clinically, no hemiplegia nor hemianopia were noted. CCM had a history of hypertension for which she was receiving medication at the time of the stroke. CCM, a high-school educated woman, was employed as a secretary pre-morbidly. Although she is bilingual |English and Afrikaans), she has resided in an English speaking environment for a long time and uses English almost exclusively.

\section{b. Aphasia testing}

The Western Aphasia Battery (Kertesz 1980) was administered in May 1985 and revealed an aphasia quotient of 73 (cut-off point 93,8) and a pattern of deficits resembling condúction aphasia. Her spontaneous speech was fluent with a mean length of utterance of 6,8 and a marked breakdown in repetition was observed.

The Bishop and Byng (1984) Lexical Understanding with Visual and Semantic Distractors, in which CCM was required to match a printed word with the correct picture, was administered. Distractor pictures included a closely related semantic picture, a distant semantic distractor, a picture which is visually similar to the target and an unrelated picture. CCM's score of 39/40 was indicative of her preserved single word level semantic ability. Relatively well preserved syntactic abilities were also observed as CCM scored $85 \%$ on the Test of Receptive Grammar (TROG) (Bishop 1982).

\section{c. Test of reading and writing:}

Detailed testing of CCM's reading and writing have been described in the previous study (Behrmann 1987). In sum, CCM demonstrated remarkably well-preserved reading skills at the single word level. She scored $100 \%$ on a lexical decision task in which she had to decide whether a string of letters constituted and English word or not. In addition, various word lists were given to her for oral reading. Reading performance was good even on irregular words (mean 96\%) which utilise the lexical route. Similarly, her ability to use the non-lexical route (segmental translation from orthography to phonology) was good as she read $83 \%$ non-words correctly. Neither imageability nor frequency played a significant role in her reading performance.

CCM's superior reading ability was in marked contrast to her impaired writing. Only on non-word writing did CCM perform relatively well $(80 \%)$, suggesting the selective preservation of the non-lexical phonological writing route. Results of several other writing tests [see Table 1 ) revealed a significant difference in her ability to write regular compared with irregular words (Bub and Kertesz list, Fisher exact test $p<0.05)$. This result was not borne out on the Roeltgen and Heilman (1984) list (Fisher exact test $p=.21$ ) possibly because this latter list is made up of low frequency words, and as such, it presents a potentially confounding interaction of variables. CCM scored poorly on the regular words of this list too, indicating a possible floor effect of this list.

Table 1: Results of CCM's writing performance across various word lists

\begin{tabular}{|c|rr|}
\hline \multicolumn{1}{|c|}{ TEST } & WRITING SCORE \\
Bub and Kertesz (1982) & $35 / 40$ & $(88 \%)$ \\
Regular words & $15 / 30$ & $(50 \%)$ \\
Irregular words & & \\
\hline Roeltgen and Heilman (1984) & $27 / 45 \quad(60 \%)$ \\
Regular words & $23 / 45 \quad(51 \%)$ \\
Irregular words & $93 / 138(67 \%)$ \\
\hline Homophone writing & $24 / 30 \quad(80 \%)$ \\
\hline Non-word writing &
\end{tabular}

CCM also performed poorly on homophone writing to dictation $(67 \%)$. This task obligatorily requires the use of the lexical procedure in order to translate the ambiguous phonological input (for example /seil/) into the correct orthographic form (either 'sale' or 'sail' depending on intended meaning and context). The regular-irregular word discrepancy, together with her poor homophone writing suggested an impairment in the use of the lexical procedure for writing.

This is further borne out by an analysis of the types of errors made by CCM. Such an analysis revealed that writing was accomplished via the preserved phonological, non-lexical route for writing. Most of her writing errors involved phonological conversion, for example tomb $\rightarrow$ "toom", ocean $\rightarrow$ "owshin", effort $\rightarrow$ "evort", ritual $\rightarrow$ "richell". Certain errors suggested that CCM was using Afrikaans rules of phoneme-grapheme conversion in her writing of English words. Examples of this include contract $\rightarrow$ "kontrak" and crime $\rightarrow$ "krime". Additionally, $/ \mathrm{w} /$ and $/ \mathrm{v} /$ were confused for example victim $\longrightarrow$ "wictim". These confusions are not surprising since CCM grew up in a bilingual community and was a fluent Afrikaans reader and writer.

In sum, the results of CCM's reading and writing testing indicates that orthographic knowledge for word recognition in reading is separate from the orthographic knowledge necessary for correct spelling in writing. While her reading was remarkably preserved, she displayed all the symptoms typi- 
cally associated with surface dysgraphia - that is, a reliance on the phonological route in writing, a discrepancy between performance on regular and irregular words and impaired homophone writing.

\section{Baseline measurement}

Prior to instituting therapy, an adequate baseline measurement must be taken to serve as the basis for comparison of outcome and the evaluation of effectiveness of intervention (McReynolds and Kearns 1983). Baseline stability and consistency are critical features which, when observed, rule out maturational and spontaneous recovery effects (Vetter 1985). As therapy was to be directed to the restoration of the lexical route through the teaching of irregular words, further spelling assessment was carried out. This assessment was loosely based on the format used by Byng and Coltheart (1986) in the evaluation of their surface dyslexic patient. Four hundred and fifty most frequent words, taken from Francis and Kucera (1982), constituted the baseline measure. Owing to the possible confounding effect of frequency, words were divided into three frequency bandwidths for testing: (i) word 1-150: frequency 69975 to 580 per hundred thousand (ii) word $151-300$ : frequency 574 to 330 per hundred thousand (iii) word 301-450: frequency 329 to 231 per hundred thousand. Testing took place over three sessions during which fifty words from each bandwidth were assessed.

Overall, CCM wrote $359 / 450$ (80\%) words correctly. Results across sessions were not statistically significant (chi squared $=1,43, \mathrm{p}>0,5)$ and hence, stability of performance was observed (session $1115 / 150$ (77\%); session $2121 / 150$ (81\%); session $3123 / 150$ (82\%)). A significant difference (chi square $=8,3, \mathrm{p}<0,01 \mid$ across frequency bands was noted with CCM scoring $87 \%$ for the most frequent items, $77 \%$ for the second group and $75 \%$ for the last frequent items.

Eighty six of the 91 incorrectly written words formed the basis of the therapy. The five words not selected comprised four words that had occurred more than once in the list and one Americanised word which was felt not to be in CCM's repertoire.

\section{TREATMENT PROCEDURE}

The aims of treatment were

a. to enhance the use of the lexical procedure in writing, through teaching CCM a group of irregular words,

b. to ascertain whether the improvement would generalise to a set of untreated irregular words.

c. to establish that the change (if any) that took place was a direct consequence of treatment.

\section{DESIGN}

In order to achieve the final aim, a multiple baseline design was used. Whereas several functions were assessed pretherapy (semantics, syntax and writing), only one function was to be treated. If improvement was a specific consequence of the treatment program, only the treated function should improve. If, however, improvement resulted from a generalised change such as increased motivation or spontaneous recovery, all linguistic functions should be affected.

In order to assess the generalisation of treatment, a crossover design of material was employed. This required that one set of words $(\mathrm{A})$ be taught prior to a second set $(\mathrm{B})$ so that one may evaluate the effect of therapy on B while $A$ is taught and vice versa. To this end, the 86 incorrect words were randomly divided up into two groups, one of 44 words and one of 42 words. These two groups were matched for frequency. Each group was further subdivided $\mid A 1$ and $A 2$, $\mathrm{B} 1$ and $\mathrm{B} 2$ ) so that shorter word lists could be taught during therapy.

Treatment took place for two one-hour sessions per week. Each list of words was taught for two consecutive sessions and intra-therapy assessment was conducted at the end of two weeks when the entire group A had been taught. Posttherapy evaluation was undertaken after both sets A and B had been covered. Figure 2 below illustrates the methodology as well as the timing of treatment.

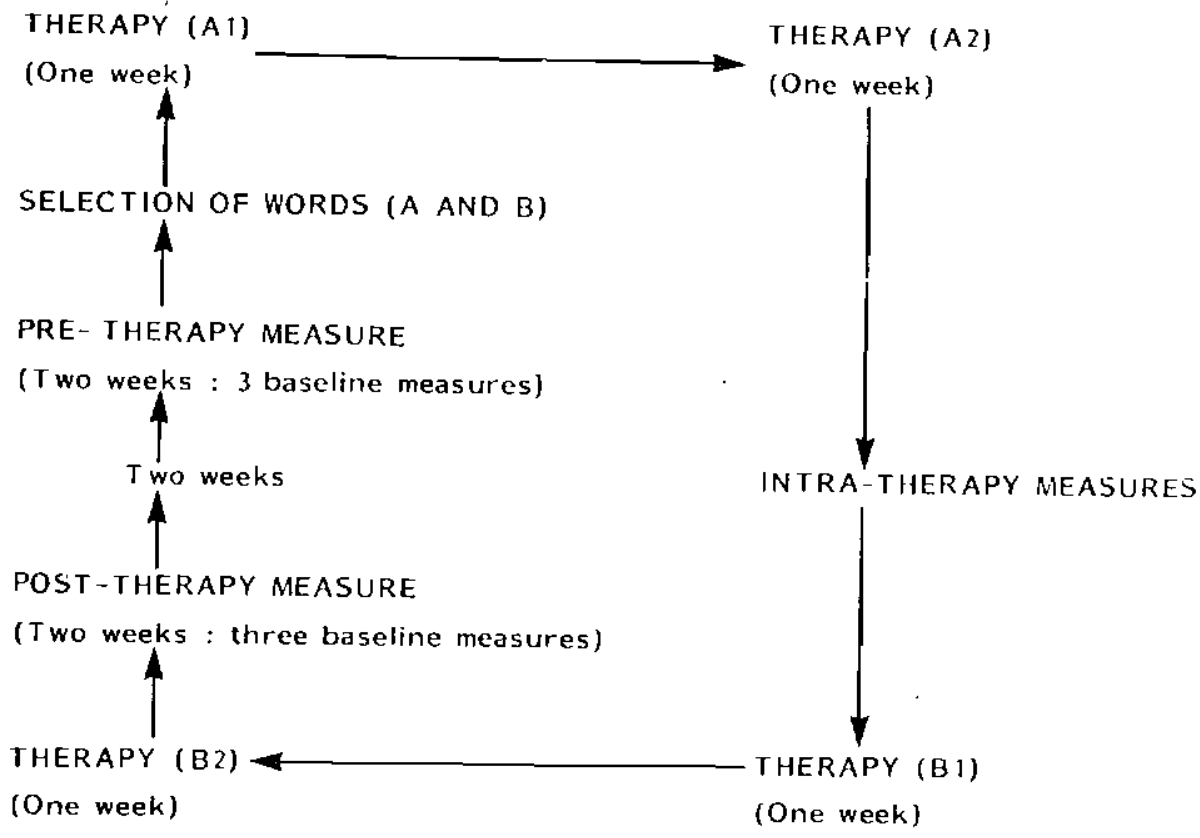

Figure 2: Methodological design and timing of CCM's treatment plan 
Several critical issues were considered in devising specific therapy strategies. In order to retain word-specific representations, a holistic approach had to be adopted and therapy had to be directed to maintaining the link between semantics and the visual form of the word. This meant that the focus of therapy would be on each individual word as a whole item and sub-lexical or part-word processing would be de-emphasized. As CCM was surface dysgraphic but not surface dyslexic, tasks which relied on reading were limited so that the focus of therapy was on the writing, and not on the reading process. Different exercises were employed in the initial and subsequent sessions. The first session involved showing CCM the target word and linking it to its meaning through the use of a dictionary. In those cases where it was possible, the word was represented pictorially. Following this, CCM was required to copy the word out several times and then to spell it aloud orally so that practice in several modalities would strengthen the link between the word and its spelling. Thereafter, she wrote the word to dictation. Home practice was undertaken after each session and involved additional copying and picture-word matching tasks. The aim of these tasks was essentially to link the orthography to the semantics and to aid the memorising of the written form of the word.

The second session involved correction and revision of the home exercises followed by a series of multiple choice tasks in which the subject selected the correct written form from several options. She then wrote the words to dictation and incorrect spellings were highlighted with coloured pens. Finally, CCM was required to write the words to dictation. Homework was given again. Treatment of Groups A2, B1 and B2 followed the same format as outlined for Group A1. Practice at home was restricted to those words which were being taught at that particular phase of the program.

Post-therapy testing was conducted after a five day break from treatment. The post-therapy baseline testing included the re-administration of all words in lists $\mathrm{A}$ and $\mathrm{B}$ as well as all words written correctly at pre-therapy testing. The order of testing was the same as that of the pre-therapy assessment.

\section{RESULTS}

A comparison of CCM's performance pre- and post-therapy revealed a significant improvement in her spelling ability following intervention (Cochran $Q$ test $\mathrm{X}^{2}=38.7$, $p>0,001)$. Table 2 illustrates the scores obtained during the pre- and post-therapy assessments. There was no significant difference in CCM's three post-therapy measures, indicating a stability in her performance across time $\left(X^{2}=0.99\right.$, $\mathrm{p}<0.5$ ).

The observed improvement was equally distributed across the three frequency bandwidths (see Table 3), suggesting a broad rather than a frequency-specific effect of treatment.

An evaluation of pre-, intra- and post-therapy measures suggested that the final improvement noted was directly attributable to intervention. As can be seen from Table 4 .

CCM obtained $91 \%$ correct spelling on the treated Group A words at the intra-therapy measure compared with the pretherapy score (McNemar's test $\mathrm{X}^{2}=38, \mathrm{p}>0.001$ ). The untreated Group B words were also markedly improved $[60 \%$ correct) compared with the pre-therapy score (McNemar's test $\left.\mathrm{X}^{2}=23, \mathrm{p}>0.001\right)$. This suggests that a certain amount of generalisation had taken place from Group $A$ to Group B at the intra-therapy stage. This was a pleasing, although not totally surprising result. Specific carry-over from Group A to Group B words was seen on certain words, for example, she learned to spell 'which' in Group A and generalised the 'wh' spelling to 'where' and 'while' in

Tab́le 2: Results obtained on baseline measures at pre-and post-therapy levels

\begin{tabular}{|c|c|c|c|c|}
\hline & & BASELINE 1 & BASELINE 2 & BASELINE 3 \\
\hline $\begin{array}{c}\text { Pre-therapy } \\
\text { Post-therapy }\end{array}$ & $115 / 150(77 \%)$ & $121 / 150[81 \%)$ & $123 / 150[82 \%)$ \\
\hline
\end{tabular}

Table 3: Results obtained within frequency bandwidths at pre- and post-therapy testing

\begin{tabular}{|c|c|c|c|}
\hline & WORDS 1-50 & WORDS 151-300 & WORDS 301-450 \\
\hline $\begin{array}{c}\text { Pre-therapy } \\
\text { Post-therapy }\end{array}$ & $131 / 150(85 \%)$ & $116 / 150(77 \%)$ & $112 / 150(75 \%)$ \\
\hline
\end{tabular}

Table 4: Results of Group A and Group B words at pre-intra and post-therapy testing

\begin{tabular}{|c|c|c|c|}
\hline & PRE-THERAPY & INTRA-THERAPY & POST-THERAPY \\
\hline Group A words & $0 / 44(0 \%)$ & $40 / 44(91 \%)$ & $41 / 44(93 \%)$ \\
\hline Group B words & $0 / 44(0 \%)$ & $25 / 42(60 \%)$ & $35 / 42(83 \%)$ \\
\hline
\end{tabular}


Group B. Similarly, the correct spelling of 'effort' learned on Group A was generalised to the correct spelling of 'effect' in Group B. The generalisation from Group A to Group B cannot be totally accounted for on this basis, however, and it is suggested that even at this intra-therapy stage, the lexical route had been activated and was being utilised for writing untreated words. Post-therapy testing on the now treated Group B words also revealed that further gains were made when spcific attention was paid to this group and a posttherapy gain of $23 \%$ over the intra-therapy score was noted in the Group B score.

There was no significant difference between Group A intratherapy and post-therapy scores (McNemar's text $\mathrm{X}^{2}=0$, $p<0,5]$, indicating that CCM was able to retain the words learned even when no practice was allowed. In sum, the post-therapy results were encouraging on several counts: intra-therapy generalization was observed; further benefit was later noted on Group B; and there was no decay on Group A indicating some longer-term effect. However, in order to ascertain whether CCM had learned something specific about the treated words or whether she had gained a more general ability to spell any set of words, the Bub and Kertesz (1982) word list was re-administered. The results revealed a significant improvement in the writing of the irregular Bub and Kertesz words (McNemar's test $\mathrm{X}^{2}=3,3$, $\mathrm{p}<0.01)$ and some additional improwement on the regular words from $35 / 40(88 \%)$ to $38 / 40$ [95\%). This finding strongly suggests that the lexical route is functional and is processing words that have not been individually treated.

In order to assess whether the observed change in writing was directly attributable to therapy and not simply a function of a non-specific variable, CCM's sentence comprehension was re-evaluated. Since sentence comprehension bears no theoretical relationship to writing, no improvement in this area is expected. Indeed, if improvement were noted, CCM's changes in writing ability might have been a result of diffuse variables rather than intervention per se. Pre- and post-therapy scores on the Test of Receptive Grammar were identical (85\%), confirming that the intervention procedure had a specific effect on writing alone. Likewise, no change in CCM's digit span was noted post-therapy, a finding which further confirms the specific effects of therapy.

\section{DISCUSSION}

The results of this study revealed stable post-treatment performance on writing /directly attributable to the intervention program/ and statistically significant improvement on treated words with generalisation to untreated words.

These findings suggest that it is possible to retrain writing through a whole-word technique in which the semantic and orthographic links are strengthened. The adoption of a model-based approach allowed the clinician to clearly define the nature of the underlying spelling deficit and then to develop a remediation program suited to treating the disorder. The fact that the Group B words showed some improvement in intra-therapy testing implies that the treatment of Group A words did not merely act as a rote learning of a list of words. Instead, it suggests that a more general spelling ability had been activated.

It has been previously suggested that complete restoration of lexical processing may only be achieved through word- specific attention and that the spread of generalization (Behrman 1987) is minimal. This has largely been refuted in the present case since improved lexical processing was noted on Group B words prior to its undergoing treatment and change on untreated irregular words (Bub and Kertesz list) was obtained.

Although the type of treatment program adopted in this study does not differ dramatically from traditional approaches to treatment in practical terms, it diverges in terms of its theoretical formulation. The present treatment approach is motivated by a fine-grained theoretical analysis of the subject's presenting deficits. It adopts a model of normal cognitive processing as the theoretical basis for isolating and identifying the locus of functional breakdown and for evolving a compatible treatment plan. Unlike traditional forms of therapy, the present approach provides explicit pointers for remediating the underlying cause of the deficit. Traditional forms of writing therapy do not always provide the same amount of certainty and specificity. They merely alert the therapist to the general direction which treatment should take (Perkins 1985).

Therapy studies such as the one outlined here have an additional benefit. Their results feed back into the theoretical model and either, if correct, confirm the practicality of the theory or, if incorrect, demand a modification of the model. To this end, therapy is dependent on theory and theory is enhanced and altered by therapy. It is suggested that this symbiotic relationship has much to offer clinicians working with brain-damaged subjects.

Although the therapy efficacy hypothesis was put to the test in a single subject and the results restricted in generalizability, the data contributes to the cumulative evaluation of the models used. Further case replications are imperative, however, and further developments in this field are critically dependent on the widespread application of this therapeutic approach.

\section{REFERENCES}

Beauvois, M.F. and Derouésné, J. (1981) Lexical or Orthographic Agraphia. Brain, 104, 21-49.

Behrmann, M. (1987) The Rites of Righting Writing: Homophone Remediation in Surface Dysgraphia. Cognitive Neuropsychology (in press].

Bishop, D. (1982) TROG: Test of Receptive Grammar. Abingdon, Oxon: Thomas Leach (for Medical Research Council).

Bishop, D. and Byng, S. (1984) Assessing Semantic Comprehension: Methodological Considerations and a New Critical Test Cognitive Neuropsychology, 1, 3, 233-243.

Bub, D, and Kertesz, A. (1982) Deep Agraphia. Brain and Language, $17,146-165$.

Byng, S. and Coltheart, M. (1986) Aphasia Therapy Research : Methodological Requirements and Illustrative Results. In E. Hjelmquist and L.B. Nilsson (Eds.) Communication and Handicap. Aspects of Psychological Compensation and Technical Aids. Amsterdam : North Holland Publishing Co., 1986.

Coltheart, M. (1980) Varieties of Acquired Dysgraphia. Unpublished paper, Birkbeck College, University of London.

Coltheart, M. (1983) Aphasia Therapy Research : A Sińgle Case Study Approach. In C. Code and D.J. Muller (Eds.) Aphasia Therapy. London, Edward Arnold.

Coltheart, M. (1985) Cognitive Neuropsychology and the Study of Reading. In M.I. Posner and O.S.M. Martin (Eds.) Attention and Performance XI. Lawrence Erlbaum Associates, New Jersey.

de Partz, M.P. (1986) Re-education of a Deep Dyslexic Patient : Rationale of Methods and Results. Cognitive Neuropsychology, 3, 149.177. 
Ellis, A.W. (1984) Reading, Writing and Dyslexia : A Cognitive Analysis. London, Lawrence Erlbaum Associates.

Francis, W.M. and Kucera, H. (1982) Frequency Analysis of English Usage Lexicon and Grammar. Boston, Houghton Miffin and Co.

Hatfield, F.M. (1983) Aspects of Acquired Dysgraphia and Implications for Re-education. In C. Code and D.J. Muller (Eds.) Aphasia Therapy. London: Edward Arnold.

Hatfield, F.M. and Patterson, K.E. (1983) Phonological Spelling Quarterly Journal of Experimental Psychology, 35A, 451-468.

Kertesz, A. (1980) The Western Aphasia Battery. University of Western Ontario, London, Canada.

Margolin, D. (1984) The Neuropsychology of Writing and Spelling: Semantic, Phonological, Motor and Perceptual Processes. Quarterly Journal of Experimental Psychology, 36A, 459-489.
McReynolds, L.V. and Kearns, K.P. (1983) Single Subject Experimental Designs in Communicative Disorders. University Park Press, Baltimore.

Patterson, K.E. |1986) Lexical but not Semantic Spelling. Cognitive Neuropsychology, 3, 3, 341-367.

Patterson, K.E. and Shewell, C. (1987) Speak and Spell : Dissociations and Word-Class Effects. In M. Coltheart, R. Job and G. Sartori (Eds) Cognitive Neuropsychology of Language. Lawrence Erlbaum Associates Ltd, London.

Perkins, W.H. \{1985\} From Clinical Dispenser to Clinical Scientist. Seminars in Speech and Language, 6, 1, 13-20.

Roeltgen, D.P. and Heilman, K.M. |1984\} Lexical Agraphia. Brain, $197,811-827$.

Vetter, D.K. (1985) Evaluation of Clinical Intervention: Accountability. Seminars in Speech and Language, 6, 1, 55-64. 